\title{
ENHANCING PROFESSIONAL COMPETENCE OF PHARMACEUTICAL STUDENTS IN THE ACADEMIC ENGLISH COURSE
}

\author{
Oksana Kovalenko \\ H.S. SkovorodaKharkivNational Pedagogical University \\ 04.08.1975@hnpu.edu.ua \\ Olga Afanasenko \\ O.O. Bogomolets National Medical University \\ olgaaf@ukr.net
}

\begin{abstract}
The paper presents the ideas on the integration of English language academic writing into the training of Mater of Pharmacy students. The academic literature demonstrates a powerful didactic potential for the development of both language and professional competence of students majoring in pharmacy. This fact is evidenced by the empirical study that demonstrates the finding reflected in students' graduation academic project performance. As measurement tools, we employed assessment rubrics of the graduate project, content analysis and questionnaire on teachers' feedback. The participants of the study were students from the Pharmacy faculty and teachers of English for Academic Purposes in cooperation with teachers of pharmacy. Together they outlined the criteria for the texts selection. According to the results, students mastered not only academic writing skills but also the skills of information processing and evaluation, critical thinking, presentation of information and academic integrity. The paper also presents methodological recommendations on academic texts selection for pharmaceutical students and forms of teaching academic writing to students of nonlinguistic specialities. The results of the study allow drawing the conclusion academic writing course will enhance professional competence and reduce students' misinterpreting of academic language.
\end{abstract}

Keywords: academic writing; competence; students; information processing; pharmaceutical discourse; text selection criteria.

The process of integration of Ukrainian educational systems into the world educational space significantly increases requirements to professional and academic communication to contribute to scientific insights and advances. In this regard, a crucial focus of vocational training is directed towards the mastery of foreign language communicative competence which provides a wide range of opportunities for future professional self-realisation. This trend is also supported and reflected in the system of higher pharmaceutical education.

The advancement of pharmaceutical speciality has emphasised the role of students' communicative skills in administrative and practical work, bringing communication abilities to the cutting edge of pharmaceutical students' education. The increasing number of pharmacy students, who enrol in Master programmes and write academic papers, emphasises the need for research on the academic writing teaching perspectives. Students obtaining Master of Pharmacy degree perform a great number of tasks during their study that are based on a good command of academic writing skills: pharmaceutical case reports, analysis on medicine application, proposals for new services, graduation projects, conference poster presentations and academic papers writing. Moreover, the information suggested by the latest and advanced research contributes to the expanding of the professional knowledge as well as motivates students for life-long learning. Therefore, we assume that poor academic writing skills might affect the future career. In order to find an appropriate solution to the problem, the faculty should consider the focus on students' academic writing skills development in the skill-based curricular of English Language course and Pharmaceutical Research course design. However, this step has not been done yet and Ukrainian pharmacy students do not have the opportunity to take such a course during their regular study. In such a case, we consider that extra-curricular activities might change the situation. In our opinion, writing contributes to the transformation of academic information from a scientific source into meaningful knowledge that promotes professional self-development.

The present study is aimed to analyse the influence of academic writing extra-curricular course on English language and professional competence levels that are reflected in graduation scientific projects. To equip students with academic writing skills, we initiated an extra-curricular course"Pharmaceutical research: academic writing perspectives" to train students' abilities to write academic papers, analyse, evaluate,

(C) Oksana Kovalenko, Olga Afanasenko. 2021. Published by Igor Sikorsky Kyiv Polytechnic Institute. This is an Open Access article distributed under the terms of the licence CC BY 4.0 
interpret and present academic information. Thus, we hypothesise that those students who perform extracurricular activities on academic writing would demonstrate a more proficient level of their graduation work from professional and linguistic perspectives.

\section{Theoretical background}

There has been a large volume of published studies emphasising the role of academic writing skills for university students. Most authors (Song, 2020; Owen, 2019; O'Donovan, 2018) agree that academic writing skills are essential for a successful career, however, this course causes more challenges to students than learning general English. It is explained by the close connection of writing skills and cognitive abilities of students as well as cultural and literacy background. Practical solutions to the problem are introduced in the research byThorkelson (2019) who presents the list of online resources to find topics and accomplish citation formats. In terms of managing with the content and ideas, Owen (2019) discusses pre-writing strategies for managing the content and text layout; Song (2020) proposes ideas how to teach paraphrasing with the chunking method.

The low level of academic writing skills does not only cause the misinterpretation of scientific information but occasionally leads to losing the confidence and motivation to participate in discussions (O'Donovan, 2018). Harrington \& Roche (2014) claim that many postgraduate students who enrol for post-graduate education lack fluency and accuracy in academic English because they were not introduced with the fundamentals of academic literacy in their previous studies. Among other possible reasons of students low writing skills, Angel and Martínez (2017) consider the linguistically demanding nature of academic texts. The academic content is argumentative and expository and requires advanced skills of critical literacy and information processing. Thus, if students were not trained in these skills, they could not elaborate on high-quality written product. An important issue, found in Angel and Martínez (2017) research, is the idea that not only language teachers are responsible for the development of academic writing skills and academic information interpretation. During profession-related courses, lecturers often suggest students difficult for comprehension texts without support. As a result, students are lost in the amount of information and are demotivated to work with academic discourse. We agree with this idea because language teachers are able to introduce students with language patterns and grammar, however, proper and profession-related academic texts should be selected and provided by teachers of job-related academic courses according to students background and needs.

The demand for high quality writing communication for medical and pharmaceutical students is substantiated by the expanding of the audience and a variety of documents that include presentations, pharmaceutical care plans, drug formularies, journal article critiques etc. Alsharif (2017) claims that the pharmacy profession went through transformations from being a product-based towards an informationbased field aimed at comprehensive communication skills development.

The researchers Assa-Eley et al. (2014) identify three reasons why writing is essential in the practice of pharmacy: written documents are frequently used to identify instructions or prescriptions; written communication has far greater legal standing than verbal communication; writing is becoming more important as new technologies in health care emerge. In the light of recent events, we find the research of Cherie et al. (2019) advanced and timely due to the integration of digital tools into the teaching of academic writing for Master in Pharmacy students. By applying Academic Writing Analytics web application authors highlight the importance of reflective writing skills for future scientists. This digital resource demonstrates the didactic potential to equip pharmacy students with self-critiquing and self-assessment of their papers before submission. However, we believe that prior to the implementation of this tool, it is necessary to teach students the fundamentals of academic writing in order to make objective conclusions after performing reflective analysis.

Therefore, the evidence reviewed here seems to suggest a pertinent role of academic writing skills for future successful career performance.

Data collection and analysis tools

In order to meet the study objectives, we employed a mixed research methodology. As our key task was to follow the dynamic and quality of students' knowledge, we employed such qualitative data collection tools as students' graduate projects and presentations, students' abstracts and conference papers written in English, teachers' questionnaire on assessment the results of the study. In order to analyse obtained information, we used an additional academic rubric in addition to the traditional one with the criteria for the assessment of graduation works, linguistic analysis of abstract and papers and content analysis for the questionnaire. Apart from pharmaceutical scientific content, the graduation work rubric assessment comprised such criteria as level of knowledge acquired by a student in the learning process; novelty of the topic; quality of information processing and literature review; quality of cited sources; the research structure; logic and comprehensiveness of the text and quality of the information presentated. 
Table 1.Criteria for graduation work quality assessment

\begin{tabular}{|l|l|c|}
\hline \multicolumn{1}{|c|}{ Criteria } & Grades \\
\hline 1 & Independence of work performance and initiating of scientific search & $1-5$ \\
\hline 2 & Sources credibility and variety & $1-5$ \\
\hline 3 & Academic integrity assessment & $1-5$ \\
\hline 4 & Originality and novelty of the work & $1-5$ \\
\hline 5 & Accuracy of the problem statement & $1-5$ \\
\hline 6 & Literature review quality & $1-5$ \\
\hline 7 & Coherence of work to a theme, the purpose and tasks & $1-5$ \\
\hline 8 & Logical arrangement and information analysis of the material & $1-5$ \\
\hline 9 & Practical results significance & $1-5$ \\
\hline 10 & The validity of the conclusions and their compliance with the objectives & $1-5$ \\
\hline 11 & Quality of work presentation & $1-5$ \\
\hline 12 & Participation in scientific conferences, number of abstracts and papers & $1-3$ \\
\hline 13 & Quality of abstract translation & \\
\hline
\end{tabular}

As we see from Table 1, some criteria are subject-related, other criteria are language-related. Moreover, the first criterion about the level of independence of work performance and initiating of scientific search is completely assessed by the scientific supervisor only, not by the exam board, and deal with students' experience in academic reading and writing. If students have been familiarised with academic papers, participated in conferences, published abstracts, they were active in their scientific search and were aware of the research methodology, design their project independently and initiated new ideas or changes.

With a view of methodology study, further improvement of the course and designing the syllabus, it was necessary to find out teachers' perceptions of the study results and challenges. Thus, we suggested teachers a short questionnaire. The questionnaire included the following questions:

- What skills do students need to present high-quality graduation work, apart from academic knowledge of the subject?

- What are the reasons for low-quality graduation work?

- What factors could foster the improvements of the graduation work quality?

- What improvements have you noticed in the graduation work of students from the experimental group?

- Do you consider the inclusion of the course on academic writing into the curriculum as a crucial step for expanding professional knowledge?

For the comprehensive analysis of answers, we used content and quantitative analysis. For processing the received information, we selected the following codes: academic writing skills, professional knowledge and skills, improvement, text layout, information processing, sources assessment, methodology relevance, lack of background etc. The quantitative analysis depicted the simple statistical data as a number of students with higher grades, a number of similar answers to create a results generalisation and number of positive and negative perceptions of the study results.

\section{Participants}

The extra-curricular course was introduced to Master of Pharmacy students of the BogomoletsNational Medical University. The enrollment in the course, as well as the participation in the study, was voluntary and 17 students agreed to take part in the research. The rest of the students $(n=14)$ also presented their project but without attending the course. As the study is interdisciplinary we invited 3 teachers of English language to coordinate the process from the linguistic perspective and 8 teachers from Pharmaceutical Faculty to ensure the quality of graduation projects and evaluate the educational profession-related materials suggested to students. Answers to the questionnaire were recorded as anonymous and students were informed about the grades of their graduation project without the comments on possible reasons for their grades.

\section{Procedure}

The study was implemented through four stages: extra-curricular course development, teaching students academic writing skills with the integration of received knowledge into the graduation project, presentation of the graduation project for the assessment, analysing the results. The course comprised 36 hours and lasted one semester for students obtaining a Master in Pharmacy. The classes were 2 hours each once a week. At the end of the academic year, students presented their graduation projects together with those who did not take part in the study and did not have classes in the extra-curricular course. The educational materials were selected together with teachers of Pharmacy according to students' professional needs and background. 
Among activities suggested during the course were academic papers analysis, note-making, structuring, proofreading, referencing, editing. A special attention was paid to the issues of academic integrity and plagiarism avoidance.

\section{Results}

The first set of results we obtained after the graduation projects presentations $(n=31)$ when students were assessed according to the rubric. It is worth mentioning that students who attended classes from the extra-curricular course had higher grades than those students who did not. Among those criteria in which students demonstrated the greater difference were logical research structure, level of coherence and cohesion, quality of literature review, correctness of citation and referencing, experimental results analysis, novelty of the problem statement and quality of the presentation itself. Thus, the mean total grade of those students who attended the course $(\mathrm{n}=17)$ was 58,5 points (grades sum over the number of students) and the mean grade point in the group $(n=14)$ who did not attend the course constituent 51.8 points. The comparing of the results according to criteria is presented in Fig. 1 where EG -group of students who took a course and CG- group of students who did not take a course.

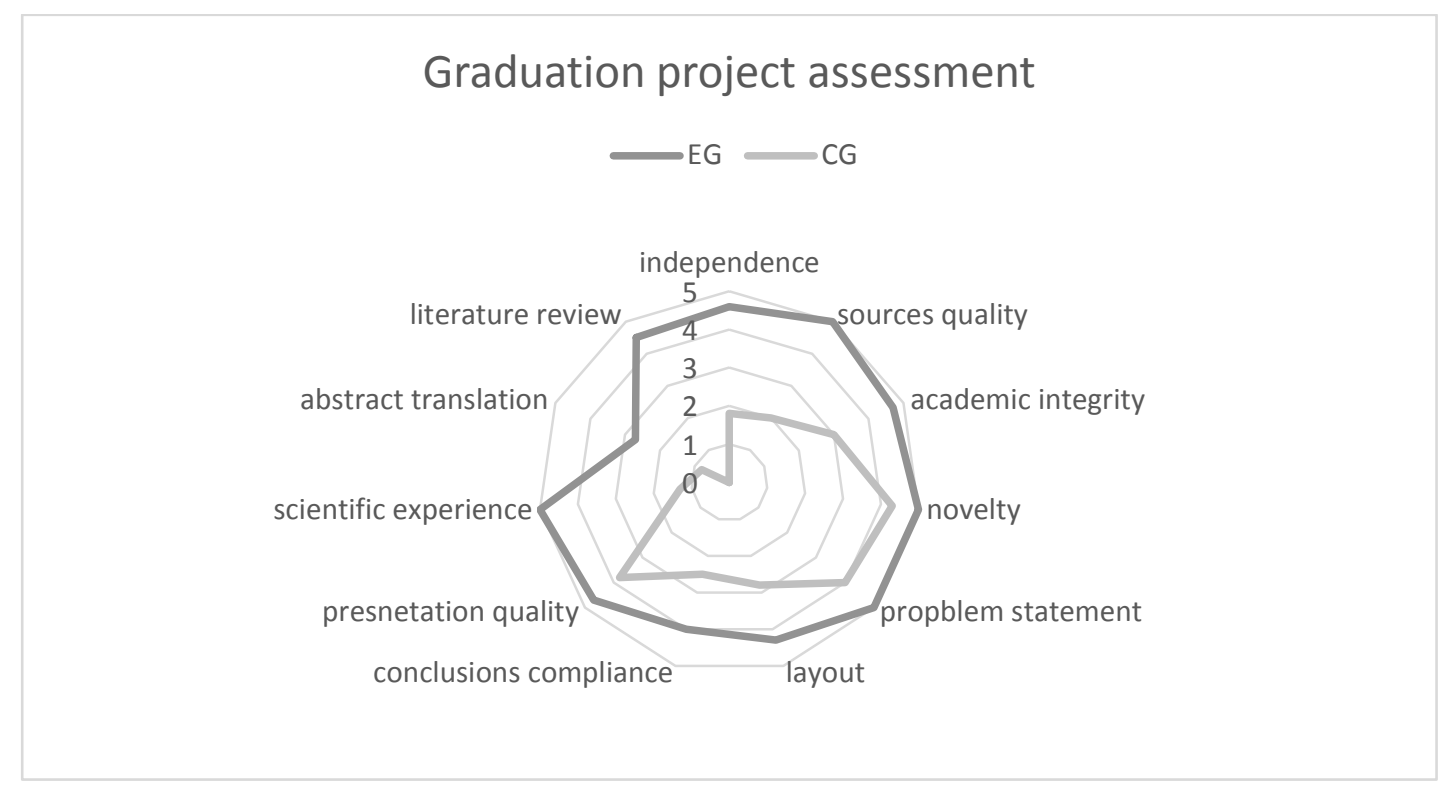

Figure 1. Results of the graduation project assessment

In the final part of the survey, teachers were asked to provide feedback on the study. Having analysed the results of the teachers' questionnaire $(n=11)$, we observed the following results:

- first question: 11 respondents agreed that students need a high level of academic writing skills, 8 respondents added knowledge and skills of the research methodology and 9 teachers noted that scientific experience is very important;

- second question: lack of experience - 11, lack of knowledge and skill - 10, lack of motivation and interest -4 , lack of resources -8 , lack of ideas to communicate -3 ;

- third question: changes in curriculum with the inclusion of academic writing and reading course -9 , more opportunities for students' participation in conferences -6 , more consulting hours- 3 , practical implementation if results -6 ;

- fourth question: the improvements are reflected in the assessment rubric;

- fifth question: 8 respondents supported the introduction of a separate course, 3 participants suggested the course as an extension of the present course on pharmaceutical research.

Taken together, these results show that there is an association between academic writing skills teaching and the quality of professional knowledge reflected in the graduation projects. The next part of our paper, therefore, moves on to discuss the causes, forms and methods of successful academic writing and professional subject integration.

\section{Discussion}

The initial objective of the project was to identify if there is an interrelation of academic writing skills development and mastering professional academic knowledge and skill for students studying for Master in Pharmacy. It was hypothesised that students with scientific experience gained through the classes of 
academic writing would perform better quality of the graduation projects. Comparison of the findings confirms our hypothesis.

Having analysed the survey results, we found out that students lacked fundamental knowledge of the academic language (relevant grammar and vocabulary structures), skills of interpretation of scientific contexts, texts organisation (following the rules of cohesion and coherence), utilising research data to produce extended written academic discourse and support arguments. We have to make a conclusion that it is due to the lack of scientific background and experience that is not provided by universities. These results reflect those of Hundarenko (2019) who also found that the lack of writing fundamentals and prior experience of Ukrainian students and the US students cause academic failures when they enter composition classes. In the academic writing course teachers tried to bridge this gap by offering students opportunities to practice while preparing conference abstracts; encouraging them to share their work via scientific social networks such as ResearchGate or Google Academy; providing individual meaningful in time feedback; addressing students towards advanced peer-reviewed credible scientific resources; developing search skills as well as skills of critical analysis, generalisation, proofreading, formulation of conclusions; explaining research planning and methodological issues.

It is obvious that in order to develop all mentioned skills and knowledge a special attention should be paid to the selection of academic texts and resources. While studying for the Master degree, students use different types of academic written texts and it is a teacher's responsibility to provide a student with texts that are relevant, updated and match professional students' needs.

There is a number of approaches for the academic texts selection suggested in the literature. Thus, Melissourgou and Frantzi (2017) suggest a genre-oriented approach where the choice of genres depends on the objectives of the course. Another approach to the selection of material is defined as the purpose-oriented choice with a focus on the text writing process (Hyland, 2019). It implies the development of text construction skills taking into account the structural features of the genre chosen by an author according to the purpose. As the purpose of the discourse is a primary goal, it is rational to start teaching academic written communication with the introduction of the target settings of writing academic texts.

We employed the second approach as the genres of the students' academic texts in pharmacy do not vary much, although the purpose of the pharmaceutical discourse is pragmatic and might change the structure and linguistic patterns as well. We should not forget that pharmaceutical texts contain specific extra-linguistic patterns that relate to the drug description, its various effects and interactions (Tomashevska, 2019). It implies a particular text layout taking into account the purpose of a text. The key areas of pharmacology are pharmacodynamics and pharmacokinetics, the study of the interaction of drugs with the organism and the study of the mechanisms of a drug action, metabolism and excretion. Also, the purpose of the text might comprise the study on therapeutic properties of substances of different origin, their production, description of various properties, forms, types, etc. As examples of the texts, we suggested students authentic peer-reviewed articles from profession-oriented journals. Such articles stimulate students' interests and, thus, suggest a solution to one of the problems teachers mentioned in the questionnaire as lack of motivation and interest. Furthermore, working with professionally-oriented authentic text, according to Rusalkina (2018) establishes a two-way connection between the student's attempt to acquire special knowledge and successfully master a foreign language.

To make the selection process far-reaching we outlined such criteria to follow as authenticity; novelty of research; semantic and informational value; professional relevance; matching the students' needs, interests and background. The last criterion enhanced students' personalised learning to foster their development as independent scientists (Lavrysh, 2020). The criterion of semantic and informational value implies the fact that the texts should be dominated by special, so-called "factual" meaningful content without emotionally expressive patterns. Authentic texts also demonstrate to students the structure and methodology of the research and stimulate critical thinking development when students try to implement that methodology in their own study. Therefore, it is important to explain to students the key principle of the text organisation that fosters the processes of comprehension and processing of information. Scientific articles as one of the types of professionally oriented texts have specific standardised sections, as well as instructions for the drug. Often, in the subject aspect, the sections of the article are similar to the content of the sections of the medicines instruction, if the article concerns the description of a medical product or recommendations for treatment. The relevance and novelty increase the level of cognitive students' activity, provide sustainable motivation to initiate and carry out research. Working with peer-reviewed articles students also gain valuable information about the principles of literature review presentation, resources evaluation and selection of source for the studying. 
From the linguistic perspective, the authentic pharmaceutical text is a source of linguistic and professional information that enhance the communicative and cognitive functions of future scientists. Apart from academic language features, pharmaceutical discourse is characterised by a large number of special terms of Latin origin, linkers, specific syntactic and semantic structures, instructive verb patterns and expressed modality. Therefore, according to the results of the graduation projects assessment, we can state that the level of academic writing skills improved that was seen from the quality of abstract translation.

However, not only teachers of English academic language can develop the mentioned skills. If there is no possibility to conduct a special course on academic writing, pharmacy educators should employ different approaches to add more academic reading and writing in their courses. One of the ways is to implement functional writing tasks that are profession-related and allow practising the writing skills, such as reports writing, abstract to papers or explanation of drug actions. Another approach is to suggest students authentic academic texts for pharmaceutical and academic critical analysis as an additional source for the topic explanation or example. Also, despite the subjects, teachers have to explain to students how to assess resources, where students should search for information and what are the rules and principles of academic integrity.

\section{Conclusions}

The present study was designed to determine the effect of academic writing skills development on mastering professional subject-related knowledge. One of the more significant findings to emerge from this study is that such interrelation exists and is evidenced by students' academic results. We can state that teaching academic writing for students majoring in pharmacy has a clear pragmatic goal to master the writing skills that are necessary for writing articles, abstracts and proposals and expand students' professional horizons for professional self-efficacy and self-realisation. Introducing the course on academic writing contributes to students' critical comprehension of academic texts, information processing, cohesion of problem with objectives and conclusions and initiating further independent research. Further research should be undertaken to explore the most suitable ways how to combine academic writing and a professionoriented subject in case of strict limitation of academic hours and resources.

\section{References:}

Alsharif, N. (2017). Purposeful Global Engagement in Pharmacy Education.American Journal of Pharmaceutical Education, 81 (10). https://doi.org/10.5688/ajpe6882

Ángel, N. \& García, J. (2017). Improving English Language Learners' Academic Writing. Gist Education and Learning Research Journal,14, 49-67. https://eric.ed.gov/?id=EJ1146679

Assa-Eley, M, Ward, T, \& Hobson, E. (2014). Communication: an overview. In: Nemire R, Kier K, Assa-Eley M (eds), The Pharmacy Student Survival Guide. McGraw-Hill.

Cherie L., Gibson, A., Buckingham, S. (2019). Pharmacy Students' Utilization of an Online Tool for Immediate Formative Feedback on Reflective Writing Tasks. American Journal of Pharmaceutical Education, 83 (6). https://doi.org/10.5688/ajpe6800

Harrington, M., \& Roche, T. (2014).Word recognition skill and academic success across disciplines in an ELF university setting. Papers in Language Testing and Assessment, 3(2), 76-99.

Hundarenko, O. (2019). Challenges of Teaching Academic Writing Skills in ESL Classroom (Based on International Teaching Experience). Revista Romaneasca pentru Educatie Multidimensionala, 11(4), 70-83. https://doi.org/10.18662/rrem/158

Hyland, K. (2019). Second Language Writing. Cambridge University Press

Lavrysh, Y. (2020). Personalized learning of foreign languages: didactic model and experimental implementation. Pedagogical Sciences: theory, history, innovation technologies, 3-4 (97-98), 66-76. https://doi.org/10.24139/2312-5993/2020.03-04/066-076

Melissourgou, M.N., \& Frantzi, K.T. (2017). Genre Identification Based on SFL Principles: The Representation of Text Types and Genres in English Language Teaching Material. Corpus Pragmatics, 1, 373-392. https://doi.org/10.1007/s41701-017-0013-z

O'Donovan, K. (2018). Why Pharmacy Students Should Master Their Writing Skills. Pharmacy Careers Spring, 12(2). https://www.pharmacytimes.com/view/pharmacy-is-ready-to-embrace-expanded-roles

Owen, J. (2019). The importance of prewriting in EFL academic writing classes. EFL Magazine. https://www.eflmagazine.com/theimportance-of-prewriting-in-efl-academic-writing-classes/

Rusalkina, L. (2018). Integration of professional and linguistic disciplines of foreign language orientation in the educational process of higher medical schools. European Journal of Humanities and Social Sciences, 6, 93-96. http://ppublishing.org/upload/iblock/404/EJH-6_2018-cor4.pdf

Song, S. (2020) Teaching the challenging but essential academic writing skill of paraphrasing. EFL Magazine. https://eflmagazine.com/teaching-the-challenging-but-essential-academic-writing-skill-of-paraphrasing/

Thorkelson, T. (2019). Tools and tips to help your students write an A+ research paper. EFL Magazine. https://www.eflmagazine.com/tools-and-tips-to-help-your-students-write-an-a-essay-research-paper/

Tomashevska, A. (2019).Development of prospective pharmacists' English lexical competence in reading and speaking through selfdirected study. Doctoral dissertation, TernopilV.Hnatiuk NPU. 